\title{
THORACOCENTESIS FOR DIAGNOSIS OF TRAUMATIC PERICARDITIS AND DIAPHRAGMATIC HERNIA IN CATTLE AND BUFFALOES
}

T.N. MISK

Department of Surgery, Anesthesiology and Radiology, Faculty of Veterinary Medicine, Sadat City University, Menofia, Egypt.

Email: $\underline{\text { tarik.misk@ vet.usc.edu.eg } \quad \text { Assiut University Email: www.aun.edu.eg }}$

\section{ABSTRACT}

Received at: $16 / 3 / 2015$

Accepted: 29/3/2015
Traumatic pericarditis (TP) and diaphragmatic hernia (DH) are common thoracic affections of cattle and buffalo. In dairy farms, thoracocentesis can be performed as an alternative field test for diagnosis of TP and DH where the availability of high output X-ray machines is limited. The aim of the study is to evaluate the success rate of thoracocentesis for diagnosis of $\mathrm{TP}$ and $\mathrm{DH}$ at field situation in 29 animals. Thoracopericardiocentesis (TPC) was performed at the left fifth intercostal space for diagnosis of TP while thoracoreticulocentesis (TRC) was applied at the right fifth intercostal space for diagnosis of DH. The study was performed on 15 cattle and 2 buffaloes suffering from TP and 1 cattle and 11 buffaloes suffering from DH. Diagnosis of these cases were confirmed by case history, clinical examination, and radiography. An 18-gauge, $15 \mathrm{~cm}$ needle with a stylette was used for the test. The TPC showed positive results in $94 \%$ of animals suffering from TP while the TRC were positive in $67 \%$ of $\mathrm{DH}$ cases. thoracocentesis is easy technique to be performed, cost efficient, and may offered as an alternative diagnostic test for diagnosis of both TP and DH in cattle and buffaloes specially in field situation.

Key words: Thoracocentesis, Traumatic pericarditis, Diaphragmatic hernia, cattle, buffaloes.

\section{INTRODUCTION}

Foreign bodies are responsible for about $70 \%$ of abdominal affections in cattle and buffaloes in Egypt (Misk 2012). Sharp foreign bodies are incriminated as the main cause of traumatic pericarditis (TP) and diaphragmatic hernia (DH) in cattle and buffalo (Misk 2012). Both diseases have high economic losses especially when there is no either medical or surgical treatment for both affections (Steiner, Edeid et al., 1992; Saini, Sobti et al., 2000; Jesty, Sweeney et al., 2005; Braun, Lejeune et al., 2007; Bexiga, Mateus et al., 2008). Few Indian authors mentioned a treated cases of $\mathrm{DH}$, however no other authors confirmed this results (Sahu, Chawla et al., 2003; Saini, Kumar et al., 2007).

Signalment, case history, and clinical examination are not sufficient for diagnosis of foreign body diseases (Narale and Bhokre 2004). Radiography was used extensively for diagnosis of abdominal and thoracic affections specially that caused by metallic foreign bodies (Misk and Semieka 2001). Ultrasonography has been reported as a non-invasive imaging modality for diagnosis of TP and DH (Flöck 2004; Mohindroo, Kumar et al., 2007; Mohamed
2010). The popularity of using ultrasonography for diagnosis of $\mathrm{DH}$ increased due to meagerness of $\mathrm{x}$-ray machines of high $\mathrm{KV}$ and $\mathrm{MA} / \mathrm{S}$ output in dairy farms. The visibility of reticular wall and its motility at the level of the fifth intercostal space (ICS) is considered positive DH. However, In late pregnant buffaloes a great pressure is applied over the diaphragm and unherniated reticulum can be seen at the level of the $5^{\text {th }}$ ICS making a false ultrasonographic positive results (Kumar and Saini 2011).

Little is written in literatures about the uses of Thoracocentesis for diagnosis of TP and DH. The aim of the present study is to throw a light on the uses of thoracocentesis as field test for diagnosis of TP and DH in cattle and buffaloes.

\section{MATERIALS and METHODS}

The present study was carried out on a total number of 29 cattle and buffaloes suffering from TP (cattle $=$ 15 , buffalo $=2$ ) and DH (cattle $=1$, buffalo $=11$ ). Cases were collected at veterinary field clinics at Egyptian villages, Alexandria University Veterinary Clinic, and Assiut Veterinary teaching hospital. 
Diagnosis of TP and DH were confirmed through case history, clinical presentation, radiography, and during labarorumenotomy surgery in somefield cases. Left side TPC was performed for diagnosis of TP while right side TRC was performed for diagnosis of DH.

Animals were prepared aseptically for thoracocentesis by clipping, shaving, and disinfection of the area just behind and above the left elbow joint in cases of TP and right elbow in cases of DH. An 18 gauge, $15 \mathrm{~cm}$ needle with a stylette was used for the test. TPC was performed at the right $5^{\text {th }}$ intercostal space(ICS) handbreadth above the elbow joint while TRC was performed at the same level at the left $5^{\text {th }}$ ICS (Fig.1.A,B). The needle is introduced horizontally until the thick skin is penetrated then the needle is directed into the fifth ICS and advanced through the thoracic wall. Redirection of the needle inside the chest may be indicated. A second trial(complete withdrawal of the needle) was performed when negative first trial result was justified. The technique was applied in standing position under sedation of Xylazine HCL (Xyla-ject ${ }^{\circledR}$ ) in a dose rate of $0.05 \mathrm{mg} / \mathrm{kg}$ injected intramuscularly. Positive and negative results of thoracocentesis were recorded.

\section{RESULTS}

A total number of 17 patients were diagnosed with TP (15 cattle \& 2 Buffaloes). Animals showed increased heart rate, muffled heart sounds, distended jugular veins, jugular pulsation, and edema of the brisket region. Radiography of the thorax revealed poor differentiation of thoracic contents. The contour of the diaphragm was lost in most cases and the cardiac silhouette was obscured in 10 patients. In 12animals, radiopaque foreign bodies were detected at the level of the heart or in the area connecting the dome of the diaphragm with the heart (Figure 2). Sewing needles and pieces of wires were the main foreign bodies presented at $x$-rays. In five animals, soft tissue density of the lung and poor radiographic details of the chest hindered the detection of any foreign bodies in the thorax (Figure 3).

The TPC were positive from the first trial in 16 animals and negative in one cattle. The aspirates were yellowish, reddish, or whitish in color with different viscosity according to the severity of the disease. The aspirate was of an offensive odor in all cases. A huge amount of pus (20 mlup to 3 liters) was aspirated from positive cases (Figure 4). In three cases just after removal of the stylette, the pus comes out spontaneously in a form of jets with the pulsation of the heart.

Twelve animals were diagnosed with DH (1 cattle \&11 buffaloes). Animals showed partial or complete anorexia with suspended rumination, recurrent tympany, and scanty feces. History revealed unresponsiveness to medical treatment. Labarorumenotomy surgery for field cases revealed presence of highly ingested food materials mixed with air (frothy ingesta) occupying the whole rumen (Figure 5). In five cases the frothy ingesta comes out spontaneously just after stabbing the rumen. Radiography revealed presence of variable sizes of rounded or vertical oval masses of a soft tissue density superimposed over the heart and in six cases exceeds the anterior border of the heart (Figure 6). In nine animals, radiopaque foreign bodies were seen within the herniated part of the reticulum.

The TRC were positive from the first trial in five buffaloes and one cattle. In two animals, positive results were recorded from the second trial. The test was negative in four patients. Infourcases, the needle needed to be redirected in order to penetrate the herniated reticulum. The aspirate was greenish reticular fluid with food particles (Fig. 2.b). The aspirate was always little in volume due to occlusion of the needle with food particles.

\section{FIGURES LEGENDS}

Figure 1: A diagram illustrating thoracopericardiocentesis (A) and thoracoreticulocentesis (B). Red: lung, Blue: heart and pericardium, Green: reticulum.

Figure 2: Lateral radiograph of the caudal thorax and cranial abdomen showing loss of details of the diaphragmatic contour in a cow suffering from TP. Note causative foreign body.

Figure 3: Lateral radiograph of the caudal thorax and cranial abdomen showing complete loos of radiographic details of the chest in a cow suffering from TP.

Figure 4: Thoracopericardiocentesis at the left fifth ICS in a cow revealed whitish pus.

Figure 5: Frothy ingesta coming under pressure during labarorumonotomy operation in a buffalo suffering from $\mathrm{DH}$.

Figure 6: Lateral radiograph of the caudal thorax and cranial abdomen in a buffaloes with a large size DH superimposed over the cranial border of the heart. Note causative foreign bodies.

Figure 7: Thoracoreticulocentesis at the right fifth ICS in a buffalo revealed greenish reticular fluid. 
$\underline{\text { Assiut Vet. Med. J. Vol. } 61 \text { No. } 145 \text { April } 2015}$

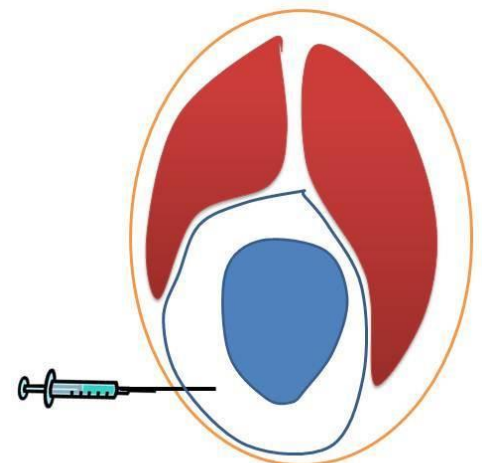

(A)

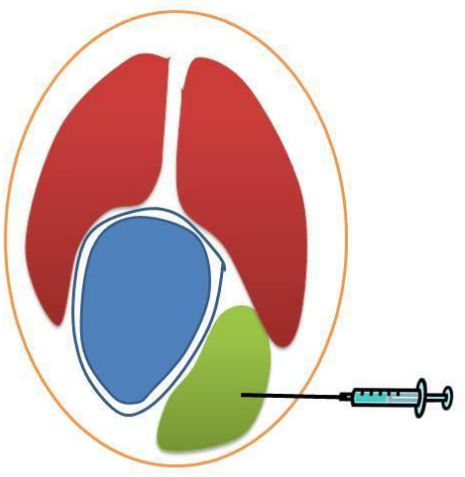

(B)

Figure 1

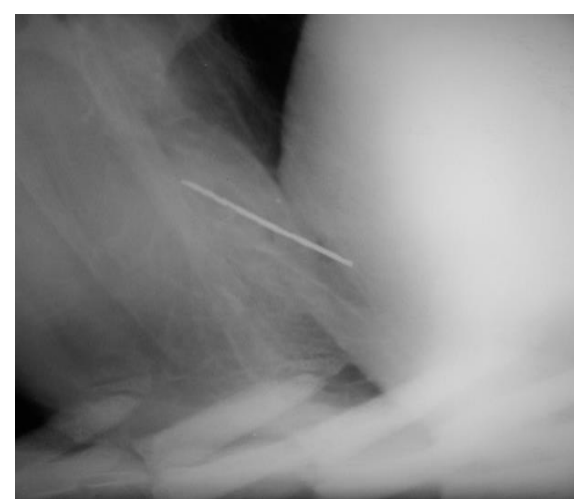

Figure 2

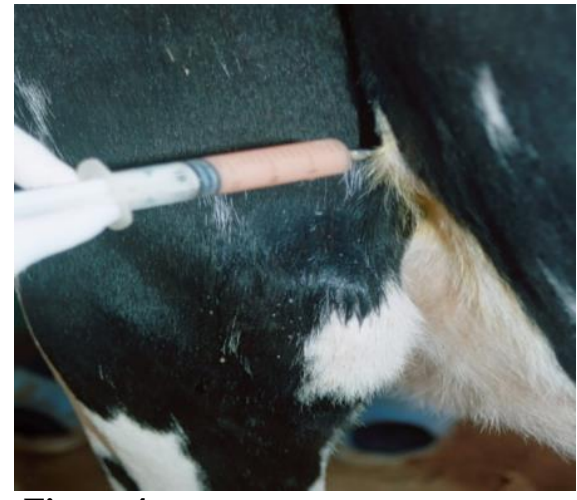

Figure 4

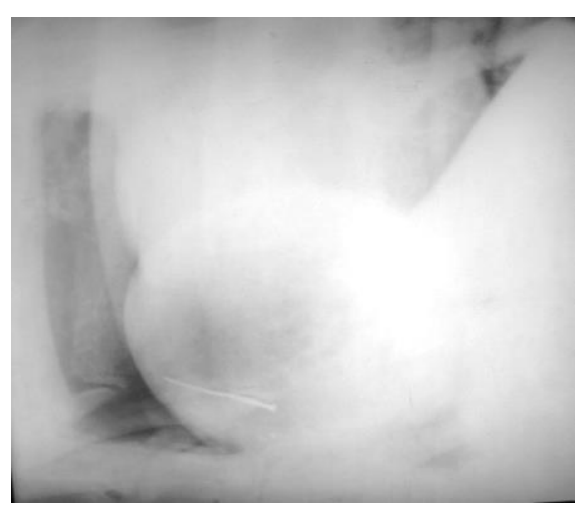

Figure 6

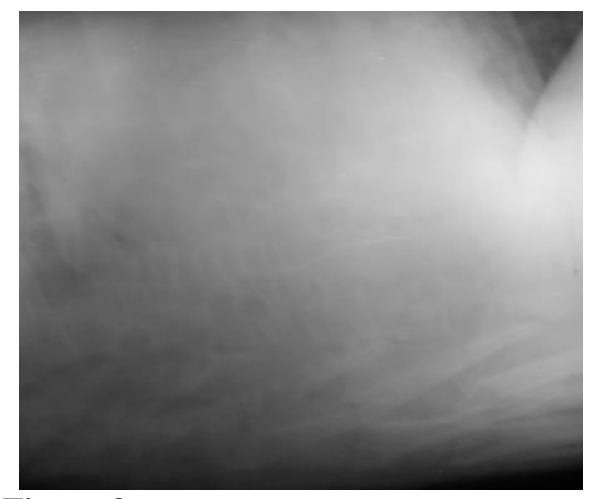

Figure 3

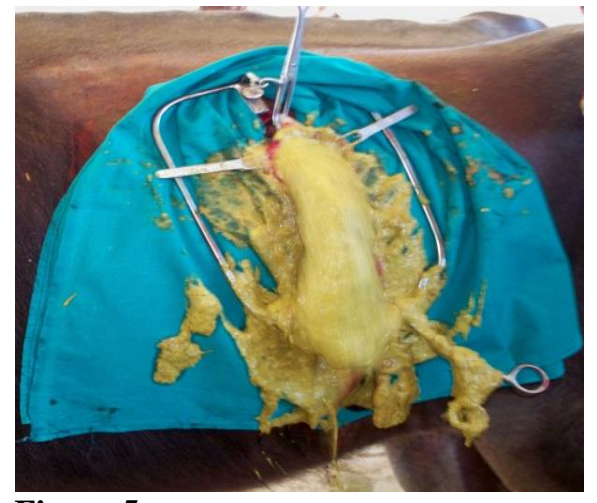

Figure 5

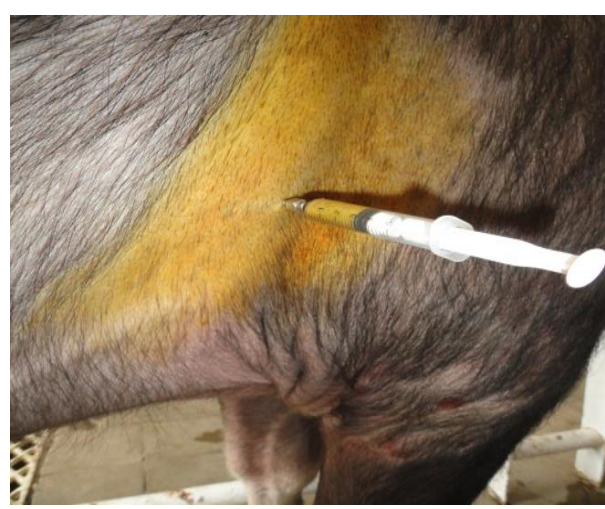

Figure 7 


\section{DISCUSSION}

The pathogenesis of swallowed foreign bodies is different in cattle and buffaloes. The swallowed sewing needles and nails are common due to raising the animals with humans at the same house in Egyptian villages however in England there are increased incidence of tire wire disease since the early 1990s (Orpin and Harwood 2012). In cattle, swallowed foreign bodies usually penetrate the reticulum and the pericardium through the diaphragm causing TP (Orpin and Harwood 2012). While in buffaloes, foreign bodies penetrate the diaphragm induce diaphragmatitis and diaphragmatic rupture which in turn leads to herniation of a segment of the reticulum into the thoracic cavity resulting in $\mathrm{DH}$ (Divers and Peek 2008; Athar, Mohindroo et al., 2010).

Higher incidence of TP in cattle and DH in buffaloes was documented. There are multifactorial causes behind these differences. The size of the abdomen and the increase of the intra-abdominal pressure during pregnancy and parturition have a role causing the disease. Animal activity is also contributed, as buffaloes are more active than cattle. Buffaloes usually descents into water cannels for swimming which addan additional pressure over the diaphragm. Studies on diaphragmatic anatomy in buffaloes revealed absence of pericardiophrenic artery supplying the lower part of the diaphragm (Sharma, Barnwal et al., 1981). The diaphragm of buffaloes has lesser collagen content than cattle thus become less elastic (Singh, Fazili et al., 2006). These findings make buffalo more susceptible for rupture of the diaphragm than cattle. This diversity in the prevalence of TP and DH in cattle and buffaloes helps in differential diagnosis.

TPC showed 94\% success rate in diagnosing TP. These results are very satisfactory for diagnosis of TP in field situation. Only one patient did not show positive results. This may be due to either inspissation of pus in the pericardial sac or an early stage of TP where the pericardium is still not reacting to the penetration.

TRC was successful in $67 \%$ of patient. Positive TRC is considering positive DH however, negative TRC may not always indicate negative DH. Radiography or ultrasound guided TRC may be needed to confirm the diagnosis. The success rate of TRC was influenced with the size of the herniated reticulum. In some cases, herniated reticulum is a little upward or backward to the centesis site. Redirection of the needle in TRC was performed if the reticular fluids were not aspirated after removal of the stylette in order to hit the reticulum. A second trial a little proximal to the first trial site may be indicated to get positive results. Further studiesonultrasound-guided
TRC may be suggested to determine the optimal location for this test.

Both TPC and TRC tests with the clinical presentation and history findings were sufficient to confirm the diagnosis even in absence of diagnostic imaging modalities specially when diagnosing TP. In field situation, thoracocentesis can be considered as an alternative diagnostic test for diagnosis of both TP and $\mathrm{DH}$ in cattle and buffaloes. The technique is easy and cost efficient. Developing experience with the thoracothentesis will decrease the error and number of trials during performing the test.

\section{REFERENCES}

Athar, H.; J. Mohindroo, et al. (2010): "Comparison of Radiography and Ultrasonography for Diagnosis of Diaphragmatic Hernia in Bovines." Veterinary Medicine International.

Bexiga, R.; A. Mateus, et al. (2008): "Clinicopathological presentation of cardiac disease in cattle and its impact on decision making." Veterinary Record162(18): 575-580.

Braun, U.; B. Lejeune, et al. (2007): "Clinical findings in 28 cattle with traumatic pericarditis." Veterinary Record161 (16): 558563.

Divers, T.J. and S.F. Peek (2008): Diseases of body system. Rebhun's Diseases of Dairy Cattle. The Netherlands, Elsevier, Amsterdam,: p. 141.

Flöck, M. (2004): "Diagnostic ultrasonography in cattle with thoracic disease." The Veterinary Journal167(3): 272-280.

Jesty, S.A.; R.W. Sweeney, et al. (2005): "Idiopathic pericarditis and cardiac tamponade in two cows." Journal of the American Veterinary Medical Association 226(9): 1555-1558.

Kumar, A. and N.S. Saini (2011): "Reliability of ultrasonography at the fifth intercostal space in the diagnosis of reticular diaphragmatic hernia." Veterinary Record 169 (15): 391.

Misk, N.A. (2012): The final report of research project "Studies on early diagnosis of different abdominal disorders with special reference to the surgical interference for treatment in cattle and buffaloes" Assiut, Egypt, Assiut University.

Misk, N.A. and M.A. Semieka (2001): "The radiographic appearance of reticular diaphragmatic herniation and traumatic pericarditis in buffaloes and cattle." Veterinary Radiology \& Ultrasound 42(5): 426-430.

Mohamed, T. (2010): "Clinicopathological and ultrasonographic findings in 40 water buffaloes (Bubalus bubalis) with traumatic pericarditis." Veterinary Record 167(21): 819-824.

Mohindroo, J. and M. Kumar, et al. (2007): "Ultrasonographic diagnosis of reticular 
diaphragmatic hernias in buffaloes." Veterinary Record 161(22): 757-758.

Narale, N.L. and A.P. Bhokre (2004): "Symptomatology of Diaphragmatic Hernia in Bovines " J. Bombay Vet. Coll 12(1 \& 2): 60-61.

Orpin, P. and D. Harwood (2012): "Clinical management of traumatic reticuloperitonitis in cattle." In Practice (30): 544-551.

Sahu, A. and S.K. Chawla, et al. (2003): "Diaphragmatic herniorrhaphy in buffaloes: clinical evaluation of 72 cases." Indian Journal of Veterinary Surgery 24: 33-34.

Saini, N.S. and A. Kumar, et al. (2007): "The use of ultrasonography, radiography, and surgery in the successful recovery from diaphragmatic hernia in a cow." Can Vet J. 48(7): 757-759.

Saini, N.S. and V.K. Sobti, et al. (2000): "Retrospective evaluation of 80 non-surviving buffaloes with diaphragmatic hernia." Veterinary Record 147(10): 275-276.

Sharma, D.N.; A. . Barnwal, et al. (1981): Haryana Agri. univ. J. Res. 11: 121-128.

Singh, J. and M.R. Fazili, et al. (2006): "Current status of diaphragmatic hernia in buffalo with special reference to etiology and treatment." Indian Journal of Veterinary Surgery 27(2): 73-79.

Steiner, A. and M. Edeid, et al. (1992): "Diaphragmatic hernia in a cow." AgriPractice 13: 37-40.

\title{
البزل الصدري كطريقه لتشخيص التهاب التامور الرضى وفتاقات الحجاب الحاجز في الابقار والجاموس
}

\author{
طارق نبيل مسك \\ Email: $\underline{\text { tarik.misk@ vet.usc.edu.eg } \quad \text { Assiut University Email: www.aun.edu.eg }}$
}

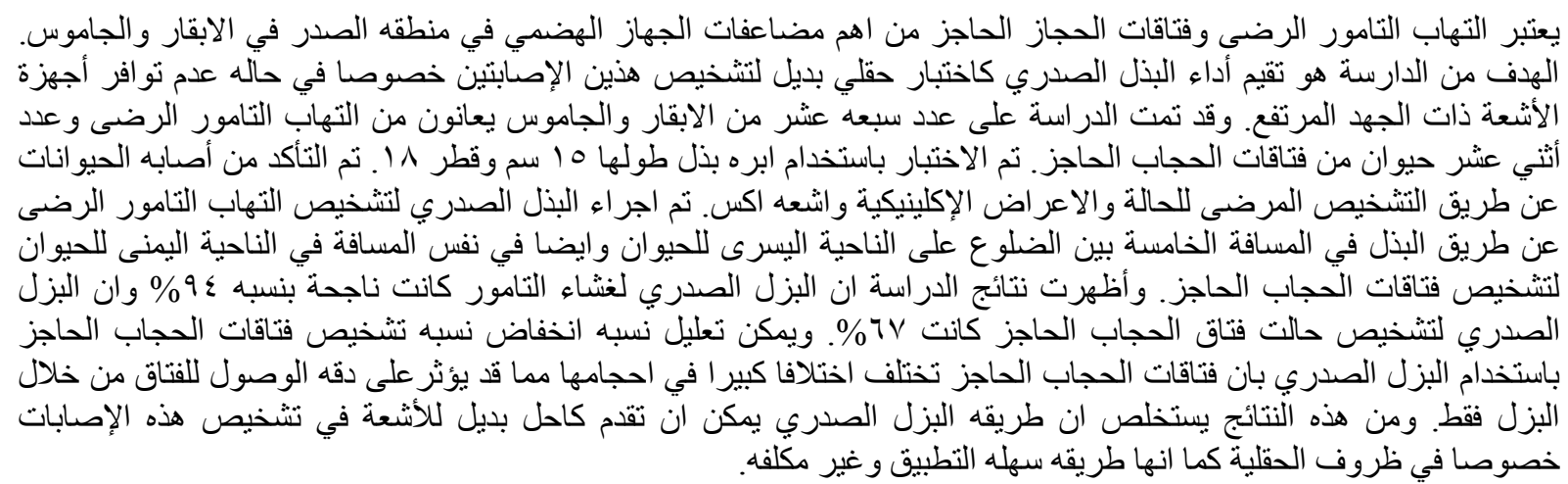

